\title{
COST OPTIMIZATION OF HIGH-SPEED RAILWAY PRE-STRESSED BOX GIRDER BRIDGE
}

\author{
Nancy Hammad \\ Civil Engineering Department, \\ German University in Cairo (GUC), Cairo, Egypt \\ Mahmoud El Khafif \\ Civil Engineering Department, \\ German University in Cairo (GUC), Cairo, Egypt \\ Nagy Hanna \\ Civil Engineering Department, \\ German University in Cairo (GUC), Cairo, Egypt
}

\begin{abstract}
This paper presents an efficient and reliable computational tool to analyze and reach the optimal design of a high-speed railway pre-stressed box girder bridge. The design and analysis of the simply supported box girder bridge is performed by using CSI bridges and SAP 2000 finite element software according to Eurocode (EN 1991-2, 2003) [5] and the Egyptian Code of Practice (ECP 201, 2012)[3]. Computer spreadsheet applications are developed for design and cost estimation of a full-span precast box girder bridge. The optimal design is achieved by selecting the efficient design variables based on the limit-of-deflection constraint. Development of the optimum design charts was evaluated through cost estimation of all major bridge components, including the foundation and sub-structure. The design variables considered in this study were girder depth, span length and the pre-stressing area. The optimum, i.e. most cost efficient design is attained at a girder depth of $2.9 \mathrm{~m}, \mathrm{a}$ span length of $32 \mathrm{~m}$ and a pre-stressing area of $347 \mathrm{~cm}^{2}$.
\end{abstract}

Keywords: optimization; cost, high-speed railway (HSR), pres-tressed box girder, simply supported girder, and full span precast construction method.

Cite this Article: Nancy Hammad, Mahmoud El Khafif and Nagy Hanna, Cost Optimization of High-Speed Railway Pre-Stressed Box Girder Bridge. International Journal of Civil Engineering and Technology, 11(4), 2020, pp. 91-105.

https://iaeme.com/Home/issue/IJCIET?Volume=11\&Issue=4 


\section{INTRODUCTION}

High-speed train operations are catching worldwide attention from the last 30-40 years since Japan introduced high-speed train services way back in early 60s. Japan has marked the comeback of the train as an important passenger mode of transport. The development of these new lines has done over a period of more than forty years between the middle of the 1950s and the current decade. Internationally the term 'High-speed' is used if the following characteristics are fulfilled: a) construction of separate lines with defined standard of highspeed, b) vehicles for high-speed traffic, and c) maximum speed of at least $200 \mathrm{~km}$ per hour and generally more than $250 \mathrm{~km}$ per hour (Givoni, 2006) [6].

Currently, construction of new high-speed railway (HSR) lines is being undertaken in a large number of countries in particular on the continent of Europe, East Asia and Japan (Givoni, 2006) [6]. In order to provide efficient means of direct, safe and high-speed transportation, bridges became a major part of HSR infrastructure. Construction of rail bridges prevents the interruption of existing lines and the occupation of land. Further they ensure the flow of traffic in high conditions of safety and comfort at any traffic speed up to the designed speed defined to the bridge and for all types of traffic crossing the structure. As a result, 50\% of the largest Chinese high-speed railway network is bridges (Yan et al., 2015) [14].

High-speed railway bridges are always long bridges that composed of large number of repetitive structural elements and require huge budget. In order to minimize the total cost of structure and save a significant amount of time, optimization of design parameters such as span length, cross section type and depth, is indispensable. Consequently, the detailed design phase is reduced and the designer can devote more time in creating talented solutions. In addition, defining an efficient construction methodology is necessary in order to save time (Yan et al., 2015) [14].

\section{LITERATURE}

In search for optimal design of bridge girder, many optimization criteria have been investigated such girder geometry, minimum weight, pre-stressing tendons and cost. Ozakca \& Taysi, (2003) [8] used the finite strip method to determine the stresses and displacement based on Mindlin-Reissner shell theory for optimization box girder shape in curved platform. The constraint conditions included limits on stress and weight. Chang et al. (2012)[2] developed a computer spreadsheets application for analysis, design and cost calculation to reach the optimal design of cast-in-place post-tensioned box girder bridge. The considered design variables were span length, section depth, web spacing, tendon profile and concrete strength. Al-Osta et al. (2014) [1] presented an application of gradient search method on the optimal design of a pre-stressed box girder for a given two or three continuous bridge deck. The optimal design is achieved through reaching the optimum arrangement of both long and short tendons and the optimum ratio of interior to exterior span. Sirca \& Adeli (2005) [12] introduced a method for total cost optimization of the precast pre-stressed concrete I-beam bridge. The cost of pre-stressed I-beam, deck concrete, deck reinforcing steel, and formwork were taken in account for cost calculation.

Multiple construction methods are available for erecting high-speed railway beams. Recently, full span launching gantry construction method is found to be one of the fastest and most reliable construction methods. This method provides erection of spans without a need for false work or temporary support. Consequently, it is considered to be the most cost efficient for multiple span erection. By this method, a precast span may be casted in a local factory and transported to the site. The transported span is allowed to move above the constructed bridge to be erected in its position by a girder-launching gantry. However, this 
method is inapplicable for continuous spans erection and the speed of span erection depends on the available number of moulds (Rosignoli, 2014) [11]. Mawlana \& Hammad (2013) [7] presented a methodology for optimizing the construction of a precast box girder bridge using full span launching gantry construction method. Interaction between genetic algorithm and a simulation model was utilized for minimization of project cost and duration depending on decision maker's requirement.

In spite of the presence of large number of the optimal design procedure, the optimal design of pre-stressed box girder subjected to special load such as HSR loads and special constraint conditions for example the very low deflection limit and minimum cost, has not been attempted. For that the main aim of this paper is to present an optimization method to find the optimum design of a single cell post-tensioned simply supported box girder. The included design variable are the girder depth, span length and the prestressing area subjected to a constrained function of deflection. The optimal design is attained with achieving the allowable deflection at the lowest cost. The object function of cost includes the cost of the superstructure, substructure and the construction method. Full span precast launching gantry construction method is considered in this study providing a proposed factory layout.

\section{MATHEMATICAL DEFINITION OF OPTIMIZATION PROBLEM}

The objective function is the total cost of the structural concrete, pre-stressing tendons and reinforcing steel, foundation, bearing, expansion joints and construction equipment. The cost of the formwork was indirectly embedded in the assumed unit cost of the reinforced concrete of the substructure. Since the proposed construction method is full span pre-casting method, no formwork was needed for the superstructure. The cost of the pre-stressing anchorage was directly embedded in the assumed pre-stressing tendons unit cost. The equipment needed for full span pre-casting method were launching gantry, tire trolley, gantry cranes and moulds required for precast concrete. A cost calculation sheet was performed for each equipment for each span length to calculate the cost. The equipment cost was calculated including purchase cost, overhead, operation cost, maintenance and repair, interest, salvage value, and depreciation value. The used price lists were assumed according to the General Authority of Roads and Bridges, (Egypt) price lists. The cost objective function could be assumed as the following:

$$
\mathrm{F}=\mathrm{Ccs} * \mathrm{Vcs}+\mathrm{Cpr} * \mathrm{Wpr}
$$

Where: Ccs is the cost of concrete in superstructure (grade 60) per unit volume, Vcs is the volume of concrete in superstructure structure, Cpr is the cost of pre-stressing tendons per unit weight, and $\mathrm{Wpr}$ is the unit weight of pre-stressing tendons.

$$
\begin{aligned}
& \mathrm{C}=\mathrm{Cr} * \mathrm{Wr}+\mathrm{Ccs}^{\prime} \mathrm{Vcs}^{\prime}+\mathrm{Ccp} * \mathrm{Vcp}+\mathrm{Cbp} * \mathrm{Lbp}+\mathrm{Cbr} * \mathrm{Nbr}+\mathrm{Cex} * \mathrm{Lex}+ \\
& \mathrm{Ceq}
\end{aligned}
$$

Where: $\mathrm{Cr}$ is the cost of reinforcing steel per unit weight, $\mathrm{Wr}$ is the unit weight of reinforcing steel, Ccs' is the cost of concrete in substructure (grade 40) per unit volume, Vcs': is the unit volume of concrete in substructure element, Ccp is the cost of plain concrete per unit volume, $\mathrm{Vcp}$ is unit volume of plain concrete, $\mathrm{Cbp}$ is the cost of bored pile per unit length, Lbp is the unit length of the bored pile, Cbr is the cost of pot bearing per piece, $\mathrm{Nbr}$ is the number of the used pot bearing, Cex is the cost of expansion joint per unit length, Lex is the unit length of the expansion joints, and Ceq is the lumped sum cost of the used equipment.

The optimization problem is to minimize the cost function presented in Eq. (1) subjected to specified constraint on deflection to achieve the required smoothness of rail for passenger comfort. According to EN 1991-2, deflection function is proposed as shown in Eq. (3). The main considered design variables are the span length (L), girder depth (d) and the pre- 
stressing area. The function F given in Eq. (2) is significantly affected by changing the span length and slightly affect by the girder depth. Figure 1 summarizes the objective function, design variables and constraint function.

$$
\Delta=\mathrm{L} / 1400 ; \mathrm{L} \leq 80 \mathrm{~m}
$$

Where: $\Delta$ is the deflection at midspan and $\mathrm{L}$ is the span length.

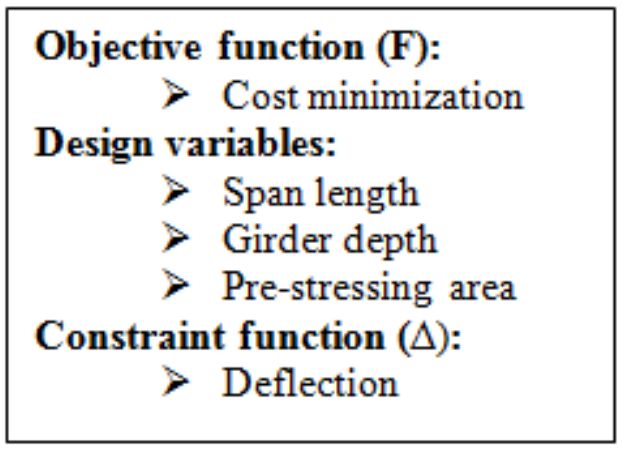

Figure 1 Objective function, design variables, constraint function used in the optimization problem

\section{OPTIMIZATION}

The optimization problem started by a feasible design and defining of the girder box section. Then design variables were progressively updating to minimize the objective function $(F)$ in Eq. (1) according to the proposed constraint function given in Eq. (3).

1. Feasible design is carried out by assigning initial values to all the variables ( $\mathrm{L}, \mathrm{d}$ and prestressing area).

2. The cross sectional geometry is defined and checked for it adequacy based on the following equations (Eq. (4) and Eq. (5))

$$
\begin{aligned}
& \mathrm{St} \geq(\mathrm{Mt}-\mathrm{RMo}) /(\mathrm{fcs}+\mathrm{Rf} \\
& \mathrm{Sb} \geq(\mathrm{Mt}-\mathrm{RMo}) /(\mathrm{fts}+\mathrm{Rfci})
\end{aligned}
$$

Where: $\mathrm{St}, \mathrm{Sb}$ are the section modulus at the top and bottom respectively, Mt, Mo are the bending moments due to total loads and own weight, $\mathrm{R}$ is the factor representing the total losses in the pre-stressing force, fci, fcs are the allowable compressive stress in concrete in initial and final stages, and fti, fts are the allowable tensile stress in concrete in initial and service stages.

3. For a chosen span length (L), initial girder depth (d(i)) is assumed and the deflection due to dead load is calculated. A new girder depth $(\mathrm{d}(\mathrm{i}+1))$ is gradually modified to new ones with constant increment $(\Delta d)$ as given in Eq:

$$
\mathrm{d}(\mathrm{i}+1)=\mathrm{d}(\mathrm{i})+\Delta \mathrm{d}
$$

4. To obtain all the allowable girder depths (d) satisfying the constraint function, the calculated deflection at each girder depth is compared to the allowable deflection.

5. The previous two steps (3) and (4) are repeated for different span length (L) starting from $22 \mathrm{~m}$ to $40 \mathrm{~m}$ with a constant incremental increase of $2 \mathrm{~m}$.

6. After finishing step (5), each span length has a range of girder depths fulfilling the constraint function. To reach the optimum girder depth (d), a certain pre-stressing area $(A p(j))$ is applied to allowable depths at each span length $(L)$ for achieving the minimum deflection at midspan and zero at the supports. Otherwise, the deflection is then reevaluated by assigning a new pre-stressing area $(A p(j+1))$ with an increment $(\triangle A p)$ as follows in Eq. 


$$
A p(j+1)=A p(j)+\Delta A p
$$

7. After reaching the optimum depth and pre-stressing area corresponding to each span length, a detailed three-dimensional analysis and design were performed for each combination according the EN 1991-2 (2003) [5] and The Egyptian code of practice for loads 2012 [3]. the objection function $(\mathrm{F})$ of cost is calculated for each combination per $\mathrm{km}$ to reach the minimum $\mathrm{F}$.

\section{DESIGN CRITERIA}

The maximum train speed is $350 \mathrm{~km} / \mathrm{hr}$; Double-lane with $5 \mathrm{~m}$ line spacing; 100 years' service. Train loads are based on EN 1991-3 (2003) [5] load assumptions. The Egyptian code of practice loads (ECP 201, 2012) [3] contains the same loads assumed by Eurocode (EN 1991-2, 2003) [5] in this part. However, Eurocode adds some important details such as accidental loads that are known by derailment loads. In addition, Eurocode puts higher restriction on the deflection of HSR. Load provisions related to the country's conditions such as earthquake, wind and temperature were assumed based on the Egyptian code of practice for loads. Figure 2 illustrated the assigned different types of loads

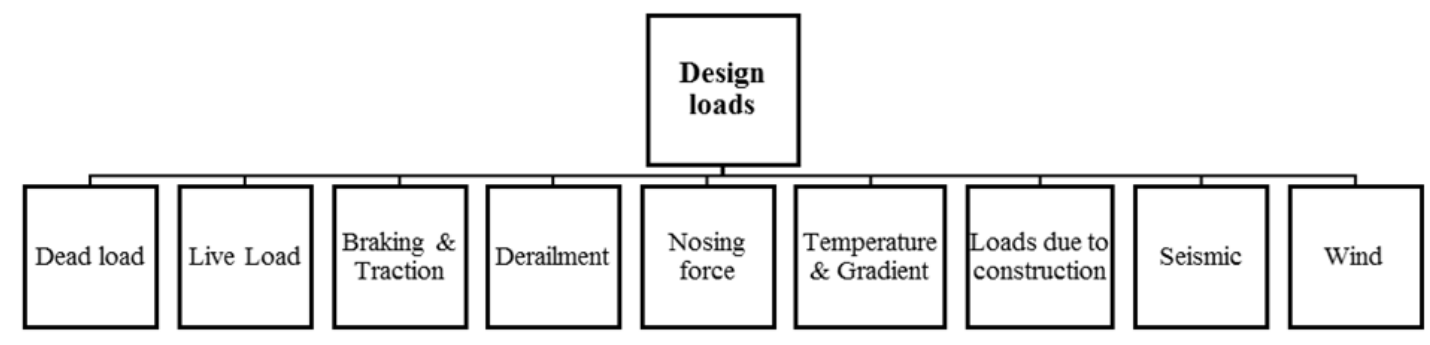

Figure 2 Flowchart of the assigned design loads

\subsection{Materials used}

Concrete: box girders were mainly composed of C60 and C40 for the other structural elements. Pre-stressed system: high strength, low relaxation strands with area of $140 \mathrm{~mm}^{2}$ and standard intensity of $1860 \mathrm{MPa}$ are used in longitudinal tendons. Steel: steel bars of grade $400 \mathrm{MPa}$ is used for main reinforcement and $360 \mathrm{MPa}$ is used for stirrups bars.

\subsection{Design Loads}

1. Dead load: self-weight, superimposed load including rails, ballast, sleepers, curb light posts and sideways, concrete creep and shrinkage were included.

2. Live load: live load is represented into three different cases which are:

a) Model No.1 (LM71): represents the moving load of the train which is composed of four concentrated vertical loads each one of $250 \mathrm{KN}$ and uniform load of $80 \mathrm{KN} / \mathrm{m}$ '.

Figure 3 represents the configuration of the moving load of model No. 1 (LM7) (EN 1991-2, 2003) [5].

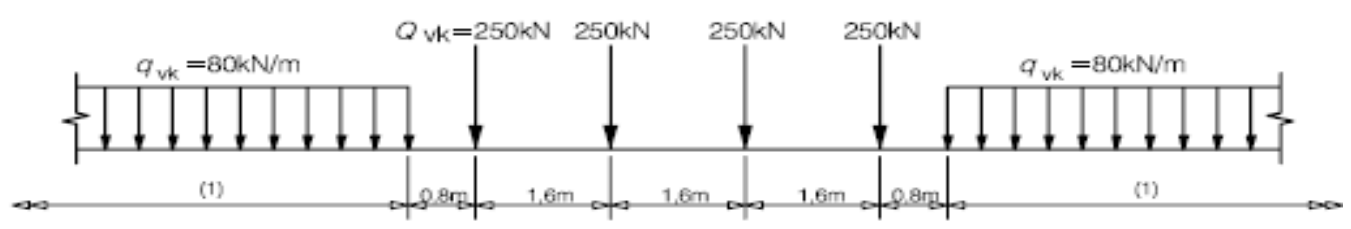

Figure 3 Flow Vertical load model no.1 (LM 71) (EN 1991-2, 2003) [5] 
b) Model No.2 (unloaded): represents the load of empty train which consists of uniformly distributed load of $10 \mathrm{KN} / \mathrm{m}$. (EN 1991-2, 2003; ECP 201, 2012) [5, 3].

- The previous models are the same as load models in the ECP 201 (2012) [3]. However, the EN 1991-2 (2003) [5] adds a third model which is:

c) Model No.3 (SW/0): consists of uniformly distributed load of $133 \mathrm{KN} / \mathrm{m}$ to represent the effect of train vertical loads on continuous bridges as shown in Figure 4 (EN 1991-2, 2003) [5].

$133 \mathrm{KN}$

$133 \mathrm{KN}$

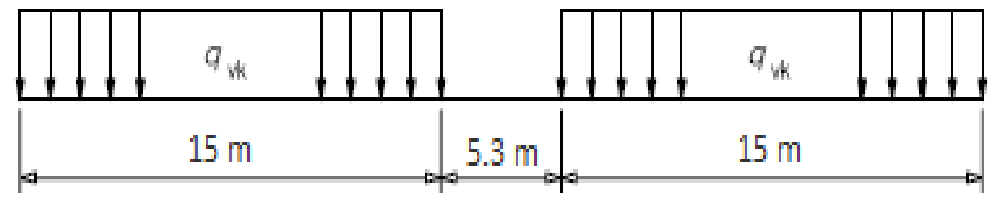

Figure 4 Vertical load model no.3 (SW/0) (EN 1991-2, 2003) [5]

The impact of high-speed train on bridges is much greater than ordinary railway bridge due to the substantial increase in the train speed. The smooth of track and the comfort of passenger will be considerably affected by the deflection of bridge. Moreover, the safety of train operation would be endangered unless keeping a stable track. For that, the impact of live load shall be greatly considered in the design.

Impact factor for carefully maintained track (EN 1991-2, 2003) [5]:

$$
Q_{2}=\frac{1.44}{\sqrt{l_{Q}-0.2}}+0.82 \quad 1<Q_{2}<1.67
$$

Where $\mathrm{L} \varphi$ : is the determinate length in meters.

3. Braking and traction: the effect of the traction and braking forces of the train shall be considered on the bridge girder. Traction and braking forces are forces that act at the top of the rails in the longitudinal direction of the track. They shall be added as uniformly distributed load over the corresponding influence length and assigned at opposite directions. The Egyptian Code and Eurocode are similar in this part. However, the calculation was done by the ECP 201 (2012) [3] to be easier.

a. Braking force is calculated by:

For $\mathrm{L} \geq 7 \mathrm{~m}, \mathrm{Q}=250+20(\mathrm{~L}-7)=\mathrm{KN}$

b. Traction force is calculated according to the following equation:

For $\mathrm{L} \geq 25 \mathrm{~m}, \mathrm{~F}=300+20(\mathrm{~L}-7)=\mathrm{KN}$

Where $\mathrm{L}$ : is the span length in meters

4. Derailment: Derailment is an accidental design situation added to consider the loading variability for risk analysis. Two design situations shall be considered. Each Situation shall be applied separately (EN 1991-2, 2003) [5].

a. Design Situation I: the train remains in the track area on the bridge deck with vehicles retained by the adjacent rail or an up stand wall (Figure 5). 1.4*LM 71 shall be assigned inside an area of width 1.5 times the track gauge on either side of the center-line of the track in the most unfavorable position (EN 1991-2, 2003) [5]. 


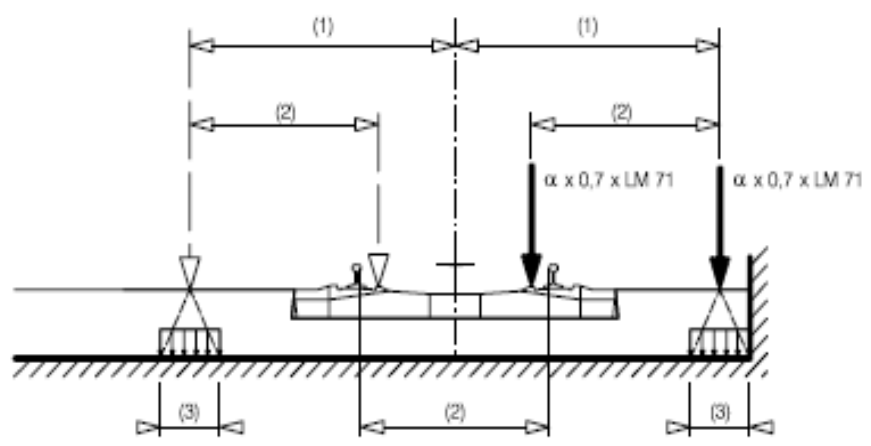

Where :

(1) maximum 1.5 (s) or less if against wall

(2) Track gauge (s)

Figure 5 Derailment situation I (EN 1991-2, 2003) [5]

b. Design Situation II: the train is balanced on the edge of the bridge (excluding nonstructural elements such as walkways) as shown in Figure 6. 1.4*LM71 shall be taken as a uniformly distributed vertical line load acting on the edge of the structure under consideration (EN 1991-2, 2003) [5].

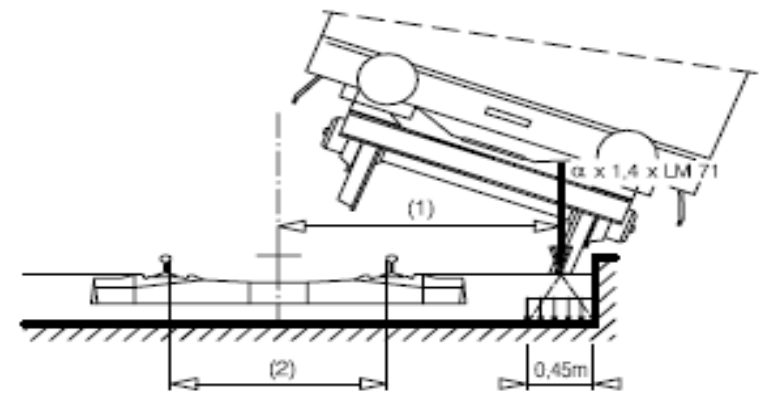

Where :

(1) Load acting on edge of structure

(2) Track gauge (s)

Figure 6 Derailment situation I (EN 1991-2, 2003) [5]

5. Nosing force: is a static concentrated force of $100 \mathrm{KN}$ that acts at the top of rails normal to the track. Nosing force shall not be multiplied by the impact factor. This force is mentioned in both, the Egyptian Code of Loads and the Eurocode (EN 1991-2, 2003; ECP 201, 2012) [5, 3].

6. Temperature and Gradient: uniform temperature change of (₹20) was assigned to all structural elements above the foundations. Non-uniform temperature change of $(\mp 5)$ was assigned to deck (ECP 201, 2012) [3].

7. Loads during construction: loads during construction are very critical loads that need to be considered especially when the construction method requires the transport of girders over the constructed girders to be erected. For that, the bridge girder was assumed to carry double of its own weight in addition to the load of the transport equipment (tire trolley).

8. Seismic load: HSR Bridge is assumed to be constructed over a dense sand soil. Based on the ECP 201 (2012) [3], the type of soil is categorized as type B. Loads were calculated by using response spectrum analysis. 
9. Wind load: wind load is composed of horizontal load and vertical load components:

a. Horizontal wind load is divided into two types which are: horizontal wind load without considering the live load, and Horizontal wind load with live load consideration.

b. Vertical wind load (ECP 201, 2012) [3].

\section{ANALYSIS}

A detailed three-dimensional analysis was performed for the pre-stressed single box girder bridge. CSI bridges finite element software was used for the longitudinal bridge analysis and SAP200 for the transverse analysis as shown in Figure 7.

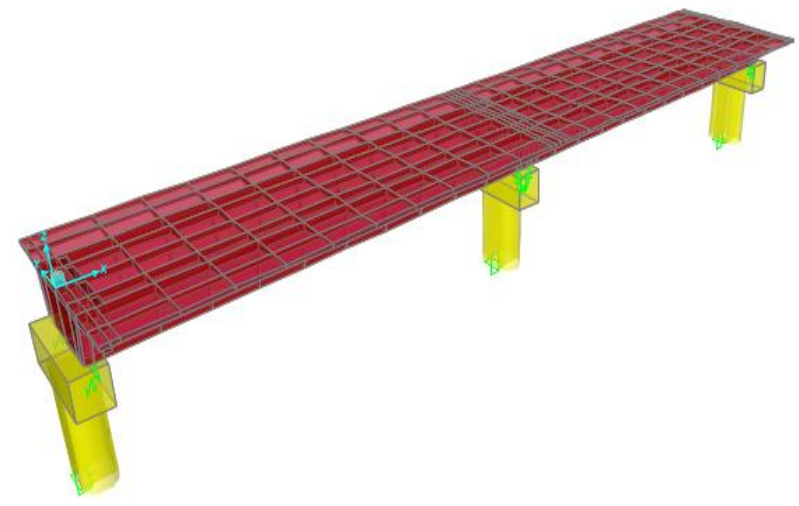

a. Longitudinal analysis

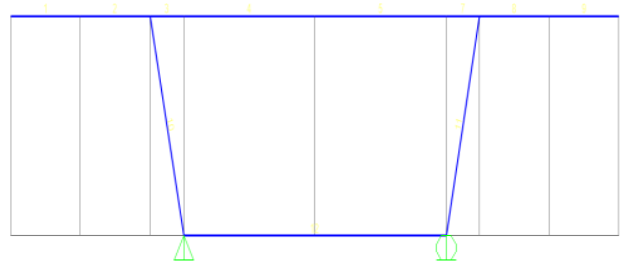

b. Transverse analysis

Figure 7 Bridge 3D analysis: (a) Longitudinal analysis; (b) Transverse analysis

The analysis started by creating a new layout line through defining the initial and final points then defining the basic properties that were required for the materials and frame sections. Creating the deck section was the next step. First, the deck section was defined as frame element to facilities stress analyzing. Then, the assigned frame element was converted into shell element to obtain the 3D model. After that, the components of the bridge such as diaphragms, bearings, bents and abutments were defined. Pre-stressing tendons were assigned. Then, loads were applied including moving loads and lanes after defining load patterns. Load combinations were defined according to the ECP 201 (2012) [3] before running the software to obtain straining actions and check deflection. The sequence of modelling procedure is illustrated in Figure 8.

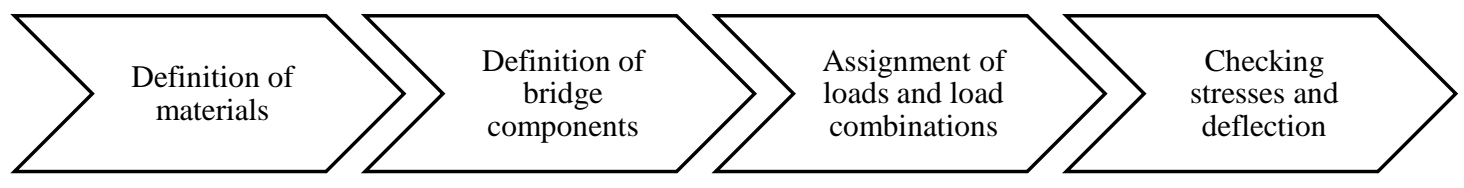

Figure 8 The sequence of modeling procedure

\subsection{Bridge Components}

- Deck section: a single box section that composed of two webs, upper and lower slab with total box depth is $2.9 \mathrm{~m}$, total deck width is $12.6 \mathrm{~m}$, width of lower slab is $5.5 \mathrm{~m}$, width of the web is $0.5 \mathrm{~m}$, depth of upper slab is 0.4 , depth of cantilever is $0.25 \mathrm{~m}$, depth of lower slab is $0.3 \mathrm{~m}$ as illustrated in Figure 9. 


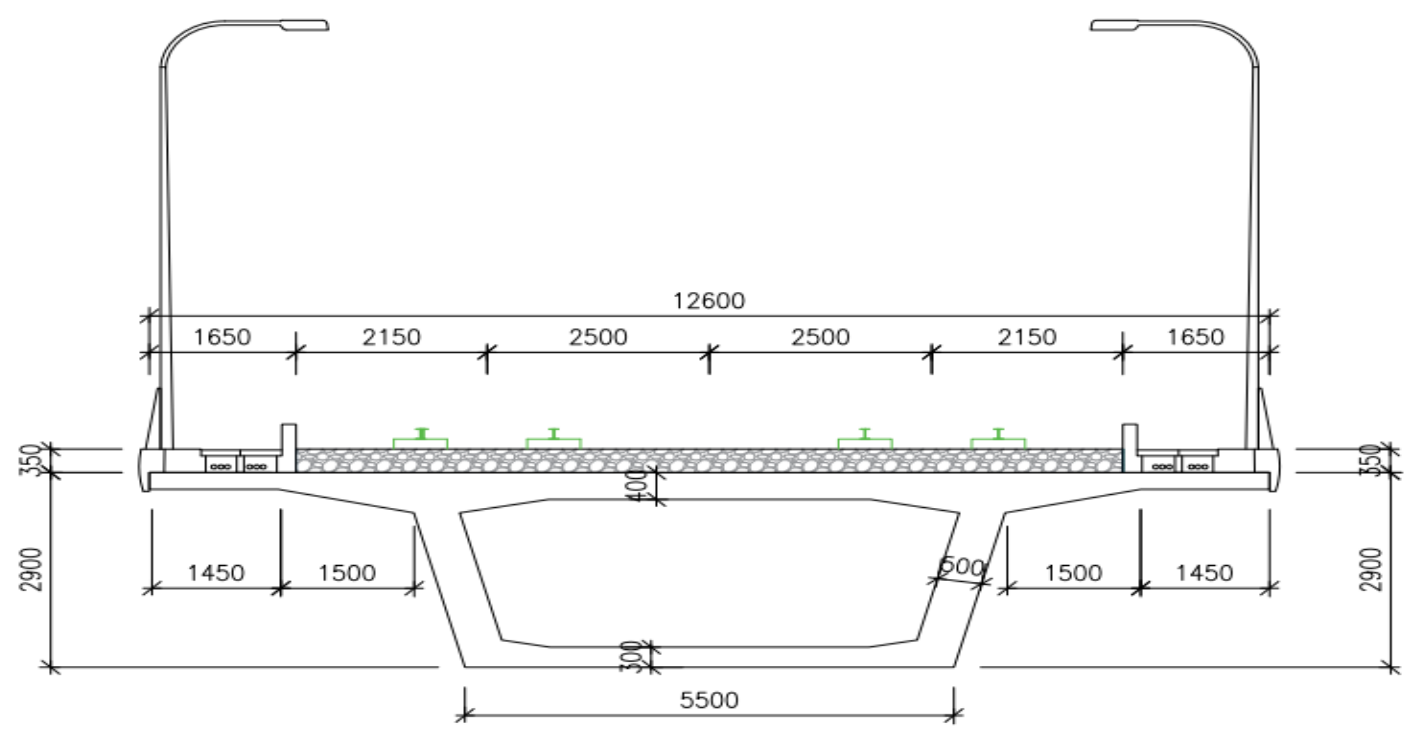

Figure 9 The assigned box section for the deck

- Diaphragm: each span contains $1 \mathrm{~m}$ diaphragm at both ends to resist high shear stress at edges and provide stiff section above the bearing.

- Bearing: bearing were distributed as shown in Figure 10 to allow longitudinal expansion from one end and transverse expansion from one side and avoid induction of internal stresses due to temperature.

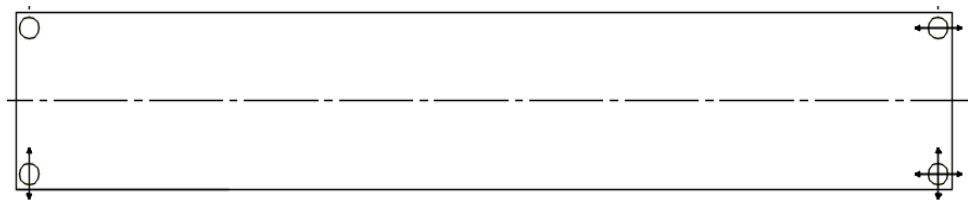

Figure 10 Bearing configuration

Table 1 key of bridge bearings

\begin{tabular}{lllll}
\hline \multirow{2}{*}{ Type } & \multirow{2}{*}{ Symbol } & \multicolumn{3}{c}{ Reactions } \\
& & $\mathbf{N}$ & $\mathbf{V}_{\mathbf{x}}$ & $\mathbf{V}_{\mathbf{y}}$ \\
\hline \multirow{2}{*}{ Fixed } & & & & \\
& & & $\mathrm{V}_{\mathrm{x}}$ & $\mathrm{V}_{\mathrm{y}}$
\end{tabular}

Longitudinally guided

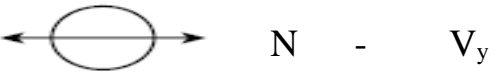

Transversally guided

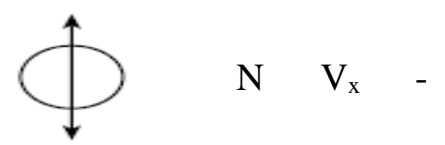

Free

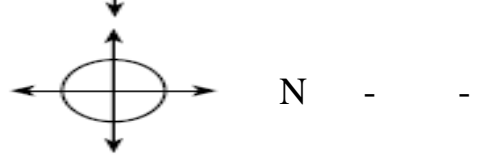

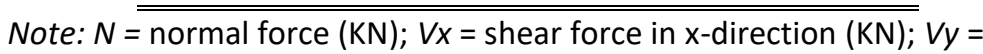
shear force in $y$-direction $(\mathrm{KN})$

- Pier: round ended pier composed of rectangular section of $1.4 \times 2.35 \mathrm{~m}$ and two ended semi circles of diameter $2.35 \mathrm{~m}$ with a pier cap of dimensions $2.3 \times 2.35 \mathrm{~m}$. 
- Pre-stressing tendons: many trails have been done to achieve two main targets which are:

a. Design consideration (resulting stress allowable stress), and

b. Deflection consideration.

Each web contains 4 tendons, each tendon composed of 31 strands, the area of each strand is $140 \mathrm{~mm}^{2}$. During tendons assignment, tendons in each web were assigned as only one tendon composed of an area equivalent to the total area of the assigned tendons.

After defining the bridge components, loads were assigned according to the previously mentioned design criteria.

\section{CONSTRUCTION METHOD}

Full span launching gantry construction method is considered to be the most suitable for erection of multiple numbers of segments. The selected construction method requires establishment of local factories for production of precast girders. These local factories could serve up to $55 \mathrm{~km}$ along the line of construction.

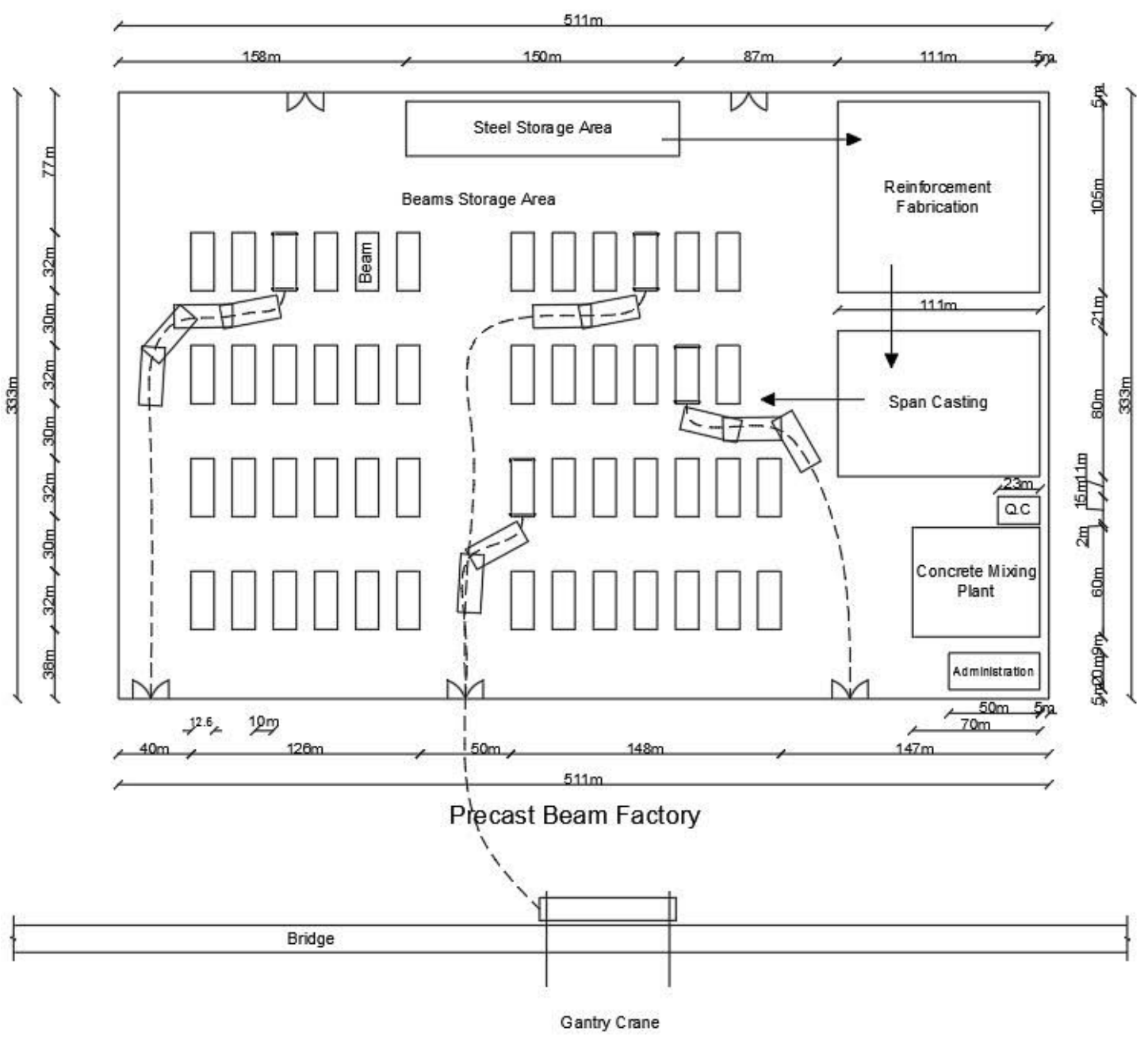

Note: $Q . C=$ quality control

Figure 11 The proposed layout for the precast beam factory

The equipment needed for the whole construction method and the local factories should be determined to be considered in the cost calculation. The factory should be composed of: a) storage area for precast spans (buffers), b) storage area for reinforcing steel and bulk materials, c) concrete mixing plant including silos, aggregate and sand storage area, d) steel 
fixing area, e) span casting area, f) quality control area, and g) Administration area. Figure 11 shows a proposed layout for the local factories. After production of beams, the precast beams are lifted by two cranes to be placed on tire trolley and transported to the bridge. Another two cranes are required to deliver the beams from the transported tire trolley to the top of the bridge. The beams are installed on position through using the erection machine which is the launching gantry (Rosignoli, 2010) [11]. Leveling the bearing is one of the most critical steps during the installation of the beams. The difference in heights between the bearings shall be less than $2 \mathrm{~mm}$, otherwise cracks could be induced (Yan et al., 2015) [14].

\section{RESULTS AND DISCUSSION}

Figure 12 shows the relationship between different combinations of span length and girder depth with the corresponding deflection due to dead load. The allowable deflection of different combinations was determined based on the constraint function $(\Delta)$. Figure 13 was plotted to show the effect of the pre-stressing area on the deflection of different girder depths at a constant span length of $32 \mathrm{~m}$. the Figure shows that the depth of $2.9 \mathrm{~m}$ with pre-stressing area of $347.2 \mathrm{~cm} 2$ has the minimum deflection at midspan which is $6.5 \mathrm{~mm}$ and zero deflection at the supports. Additionally, the span length of $32 \mathrm{~m}$ with depth $2.9 \mathrm{~m}$ is one of the safe combinations that occurred in the previous study. It is obvious that the total deflection is much less than the deflection resulting from the dead load only due to the camber caused by the pre-stressing. The negative part of the graph (Figure 13) is considered to be unsafe. Figure 13 is an example for the study carried on each span length to reach the optimum combination between girder depth, span length and the pre-stressing area as shown in Table 2.

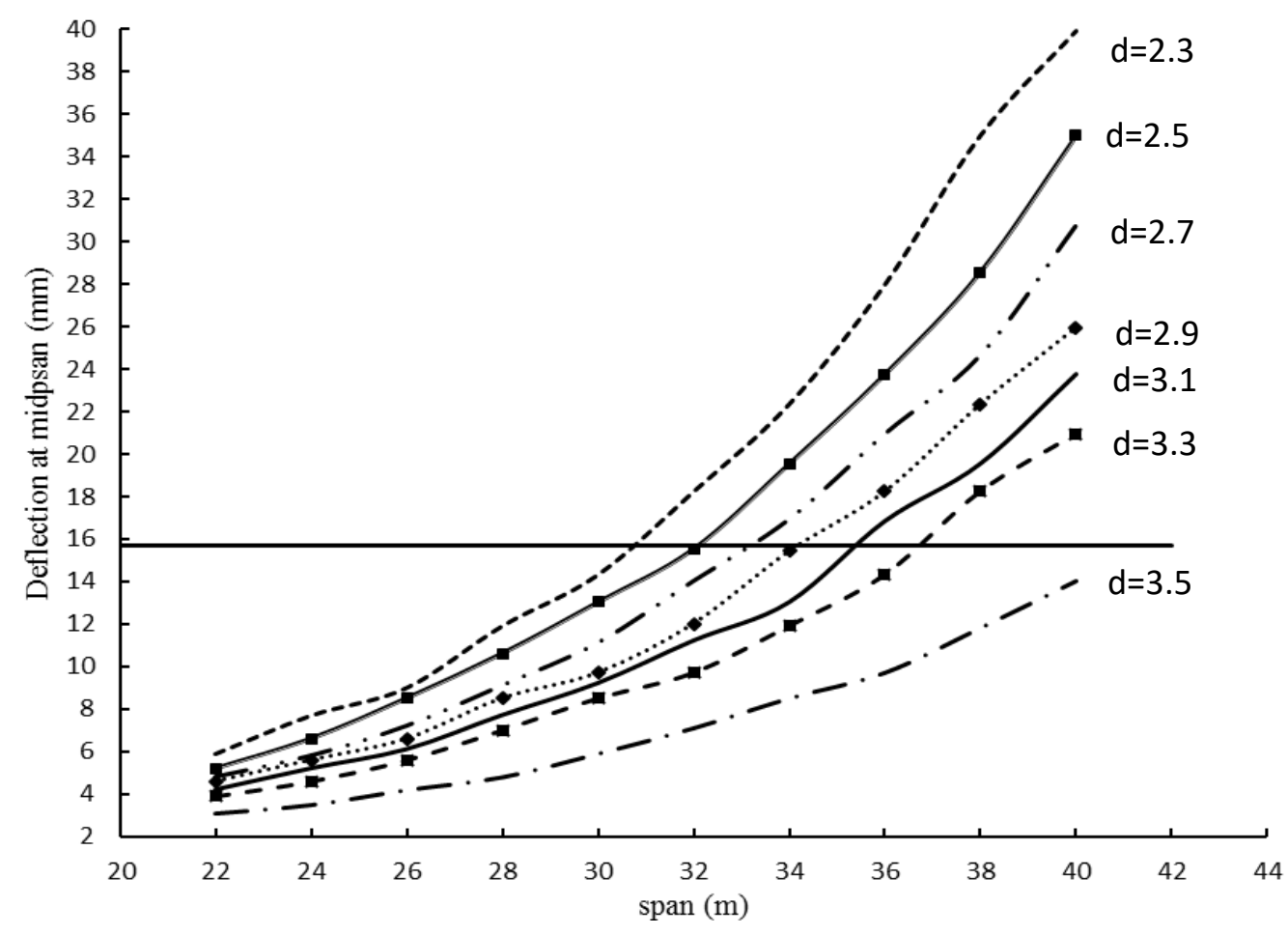

Figure 12 The effect of girder depth variation on the deflection due to dead load for each span length 


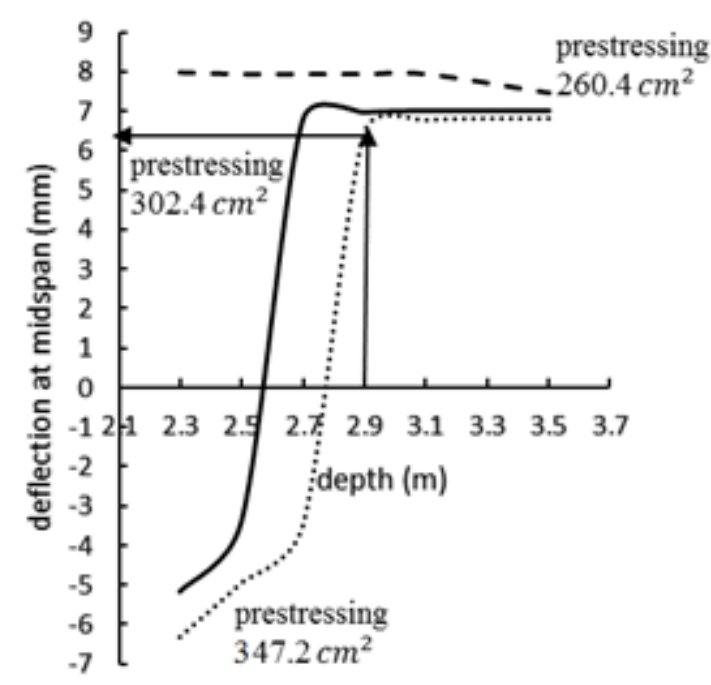

a. depth- midspan deflection

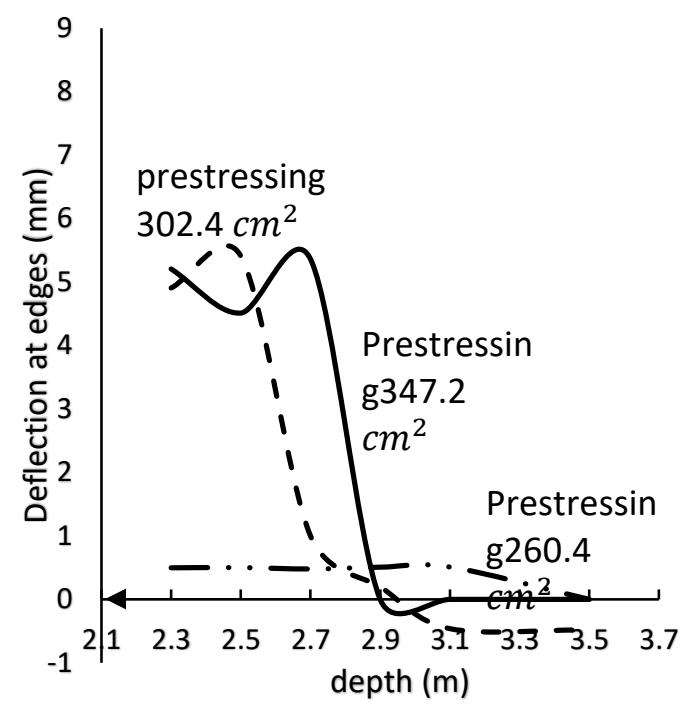

b. depth-edge deflection

Figure 13 Depth to deflection relationship with respect to different pre-stressing area at span length of 32 m: a. depth- midspan deflection; b. depth-edge deflection

Table 2 The optimum design combination

\begin{tabular}{ccccc}
\hline \hline Combinations & Span & Depth & \multicolumn{2}{c}{ Pre-stressing } \\
\hline & $(\mathrm{m})$ & $(\mathrm{m})$ & Cables & Strand \\
Combination 24 & 24 & 2.4 & 6 & 31 \\
Combination 26 & 26 & 2.6 & 6 & 31 \\
Combination 28 & 28 & 2.6 & 8 & 27 \\
Combination 30 & 30 & 2.6 & 8 & 31 \\
Combination 32 & 32 & 2.9 & 8 & 31 \\
Combination 34 & 34 & 3.3 & 8 & 31 \\
\hline \hline
\end{tabular}

For determining the most economic combination, the variation of cost per $\mathrm{km}$ for each combination was plotted as given in Figure 14. It is clear that the combination 32 is the most economic combination that could save up to $2.4 \%$ of the total cost per each $\mathrm{km}$. The reason beyond the partial increase in the cost of combination 28 per $\mathrm{km}$ relative to the previous combinations is the increase in the required number of bored pile. The difference between the different combinations costs are not very considerable for short distance, however for long distance projects the difference becomes very significant. After determining the optimized design combination, the cost of mobilization, equipment used inside the factories needed for the production of precast spans, and the rail track system excluding the cost of the rolling stock and trains was added to the previously calculated cost to be able to estimate the entire cost of one $\mathrm{km}$. The entire cost was approximately doubled (increased by 195\%). The following chart (Figure 15) shows the entire cost breakdown to highlight the percentage of different sectors. It is clear that rail track systems represent the highest part of the entire cost which is $46.7 \%$ followed by the cost of the superstructure, then the cost of substructure and mobilization. 


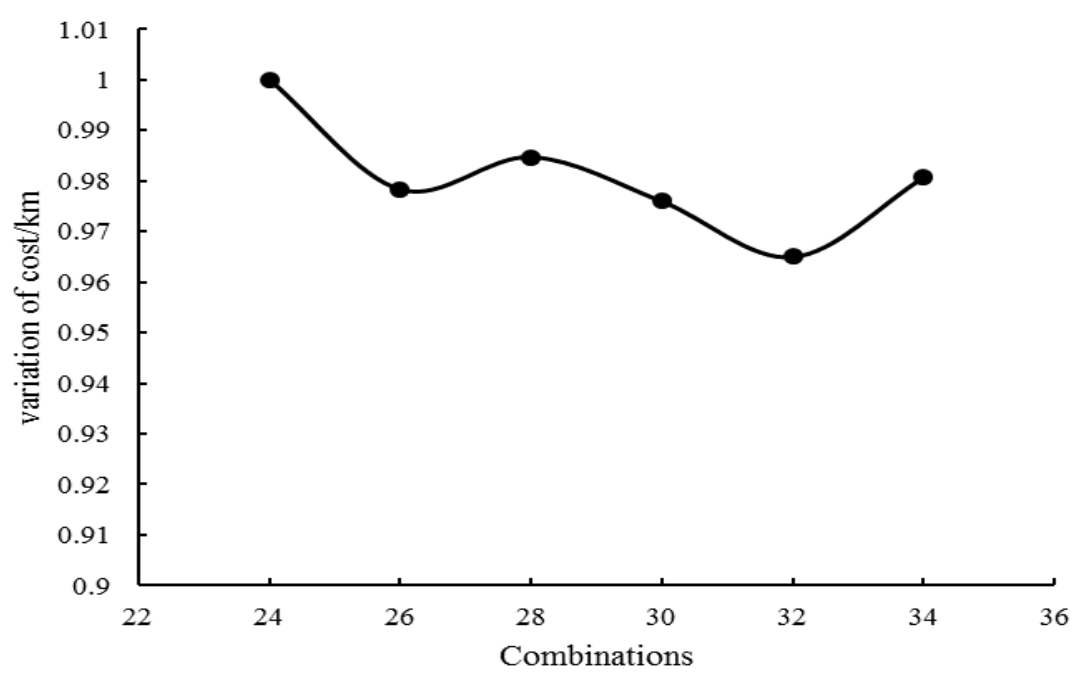

Figure 14 Span length to cost $/ \mathrm{km}$ relationship

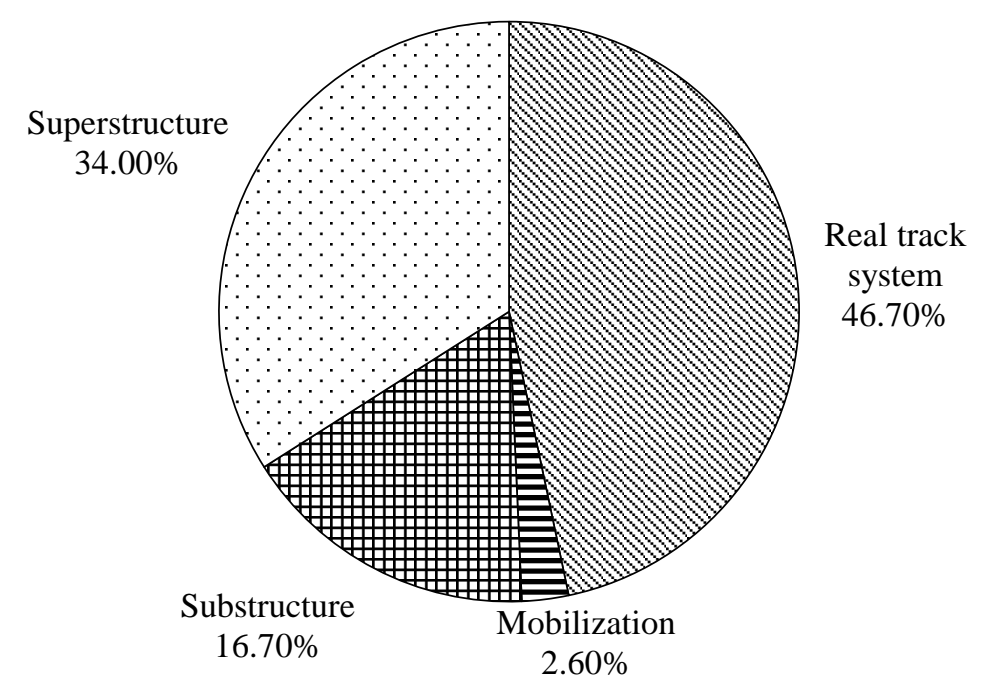

Figure 15 Entire cost distribution

\section{SENSITIVITY ANALYSIS}

Sensitivity analysis was carried out to study the effect of the design variables on the unit cost of the bridge. Several analysis and trials were conducted to determine the effect of the girder depth and the pre-stressing area on the unit cost variation. Factor $\eta(\eta=C m / C n)$ is calculated where $\mathrm{Cm}$ is the cost of the studied case and $\mathrm{Cn}$ is the cost of the optimized combination and plotted versus the change in girder depth and pre-stressing area as shown in Figure 16. The Figure shows that the unit cost decreases with the decrease in the pre-stressing area. With increasing the pre-stressing area, the volume of concrete slightly changes, however the effect of pre-stressing area on the total unit cost is higher than the concrete volume effect. In contrast, the unit cost increase with increasing the girder depth due to increasing the required pre-stressing area to compensate the decrease in the concrete resistance and keep fulfilling the allowable stress and serviceability limit. 


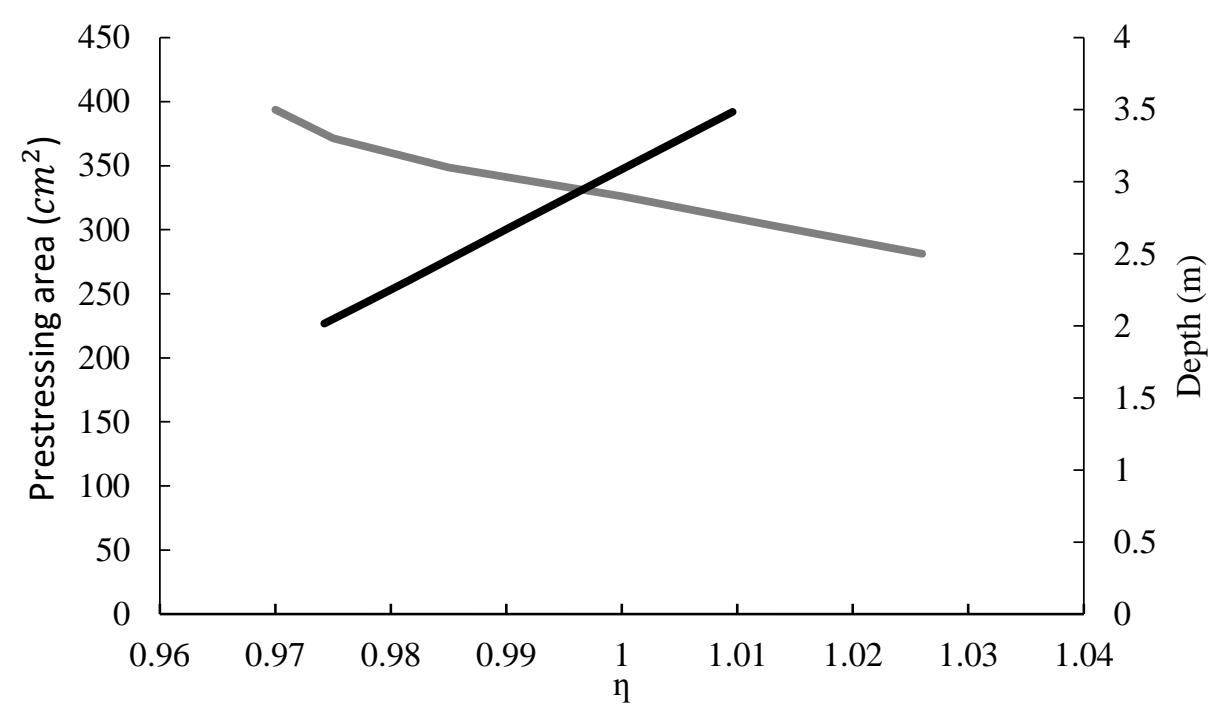

Figure 16 The effect of pre-stressing area and girder depth on the cost variation

\section{CONCLUSIONS}

Based on the results and discussions presented in this study, the following conclusions were drawn:

- The suggested optimization procedure could be developed by any generalized computer program and rapidly determine the optimum girder depth, span length and the prestressing area.

- the optimum design is achieved at span length of $32 \mathrm{~m}$, girder depth of $2.9 \mathrm{~m}$ and prestressing area of $347 \mathrm{~cm} 2$.

- Cost optimization is an efficient tool for reaching the optimal design variables that results in huge reduction in the entire project cost.

- The total cost of the bridge components has increased by $195 \%$ (approximately doubled) after addition of the cost of mobilization, equipment used inside the factories needed for the production of precast spans, and the rail track system excluding the cost of the rolling stock and trains.

- The cost breakdown analysis showed that the rail track system represents the highest part of the entire cost (46.7\%) followed by the cost of the superstructure, the cost of substructure, and mobilization.

- The performed sensitivity analysis revealed that the unit cost increases with decreasing the girder depth due to increasing the pre-stressing area required to satisfy the constraint limits and attain the optimal design.

\section{REFERENCES}

[1] Al-Osta, M. A, Azad, A \& Al-Gahtani, H. J. Optimization of Continuous Post-Tensioned Concrete Bridge Girders of No-Uniform Depth. Arab Journal of Science Engineering, 37(1), 2012, pp. 265-276.

[2] Chang, B., Mirtalaei, K., Lee, S., \& Leitch, K. Optimization of Post-Tensioned Box Girder Bridges with Special Reference to Use of High-Strength Concrete Using AASHTO LRED Method. Advances in Civil Engineering, 2012.

[3] ECP 201. Egyptian Code of Practice for Loads, 2012. 
[4] ECP 203. Egyptian Code of Practice for Concrete Design, 2007.

[5] EN 1991-2. Actions on Structures (Traffic Actions on Bridges), 2003.

[6] Givoni, M. Development and impact of the modern high-speed train, Transport Reviews, 26(5), 2006, pp. 593-611.

[7] Mawlana, M., \& Hammad, A. Simulation-based Optimization of Precast Box Grder Concrete Bridge Construction Using Full Launching Gantry. 4th Construction Specialty Conference, Montreal, Quebec, 2013.

[8] Ozakca, M., \& Taysi, N. Analysis and Shape Optimization of Variable Thickness Box Girder Bridges in Curved Platform. Electronic Journal of Structural Engineering. 3, 2003, pp. 1-22.

[9] Public of Authority for Roads and Bridges, Arab Republic of Egypt bridges.

[10] Rosignoli. M. Self-launching erection machines for precast concrete, 2010.

[11] Rosignoli, M. Full-Span Precasting for Light-Rail Transit and High-Speed Railway Bridges, China, 2014.

[12] Sirca, G., \& Adeli, H. Cost optimization of Pre-stressed Concrete Bridges. Journal of Structural Engineering. 131(3), 2005, pp. 380-388.

[13] Waggoner, F. Design guidelines for high-speed train aerial structures, California High speed Rail Train Project, 2009.

[14] Yan, B., Dai, G., \& Hu, N. Recent development of design and construction of short span high-speed railway bridges in china. Engineering Structure, 100, 2015, pp. 707-717. 